\title{
Social Aspects of Drug Addiction in Sri Lanka
}

\author{
Isma Lebbe Mohamed Mahir ${ }^{1} \&$ Thaseem Mohamed Fathima Wazeema ${ }^{2}$ \\ ${ }^{1}$ Department of Social Sciences, South Eastern University of Sri Lanka, Oluvil, Sri Lanka \\ ${ }^{2}$ Department of Sociology, South Eastern University of Sri Lanka, Oluvil, Sri Lanka \\ Correspondence: Isma Lebbe Mohamed Mahir, Department of Social Sciences, South Eastern University of Sri \\ Lanka, Oluvil, Sri Lanka. E-mail: ilmmahir@seu.ac.lk
}

Received: January 15,2020

Accepted: April 7, $2020 \quad$ Online Published: May 19, 2020

doi:10.5539/jpl.v13n2p54

URL: https://doi.org/10.5539/jpl.v13n2p54

\begin{abstract}
Social problems are rapidly increasing in modern societies due to various reasons. One of these is drug addiction, which has become a major issue in the contemporary world, as it is proving to be a serious social problem in both developing and underdeveloped countries. This review article that focuses on the social aspects of drug addiction in Sri Lanka is based on secondary data obtained from the published works of different authors; they provide details about the identity of drugs, drug addiction and the increasing number of addicts in Sri Lanka. Drug addiction has become an important issue due to its severe impact on public health, its tendency to encourage crime, cause diseases, poverty and destruction of family life in Sri Lanka. Heroin and cannabis (marijuana) are found to be the most commonly used drugs in Sri Lanka. Laws and policies designed to control drug abuse and regulations on drug addicts have not brought any major change or desired outcome in the Sri Lankan drug scene. Drug users in Sri Lanka get their supply of drugs from the underground drug market, which has its internal and external sources. Rehabilitation of drug addicts has become an urgent need in the country to protect its valuable citizens who are needed to build a sustainable nation that is free from drugs. Drug addiction is preventable and can be managed successfully if every citizen of the country gives his/ her full support and contribution.
\end{abstract}

Keywords: drug addiction, drugs, rehabilitation, social problems

\section{Introduction}

Since ancient times, human beings have always had a strong attachment to their social world and so maintained an intimate, cooperative and long-term relationship with one another. People adapted and organized themselves to realize their common goals, and this generally brought positive and desired outcomes, as can be seen throughout history. The Industrial Revolution and now Globalization have changed the nature of society profoundly and turned it into a collective of complexities totally unlike anything that had existed before in any traditional society (Giddens, 2001). These changes and complexities have created and are still creating various social problems among people. Social problems are the general issues or concerns that were always present but have dramatically increased in contemporary society (Rao, 1990). A number of social problems exist in the world today such as teenage pregnancy, drug addiction, poverty, domestic violence, child abuse, prostitution, road accidents, divorce and crime, etc., all of which have adverse effects on individuals and societies.

Drug addiction has lately become one of the biggest social problems in the modern world, being prevalent in developed, developing and underdeveloped nations in this modern era of globalization. Nevertheless, there are many who would easily conclude that drug addiction is a problem that affects solely the addicts (Dissabandara et al., 2009). Most of the persons who engage in drug abuse would say that taking drugs is a personal matter and that their individual behaviour harms only them and not others. However, all know that it is not as simple as what the drug addicts' claim. It is a well-known truth that drug addiction affects not only the individuals who take drugs but also their family members, the society and the country. Drug addiction is not a simple matter that affects only a few individuals. It is a complex, multi-faceted, all pervading social problem faced by most countries in the world. Drugs are harmful to humankind and the whole of society not only because of their addictive nature, but also because most of the drug addicts are the youth whose future is likely to be jeopardized; they also create problems for other people like their parents, school authorities, employers and so on (Brill, 1966). 
Drug abuse and Drug addiction are not a recent phenonomenon. Millions of people around the world have lost control of their own lives by falling prey to drugs. Particularly, usage of illicit drugs has risen very sharply throughout the world in the last two decades. Many people have started to use drugs without giving a second thought to the negative impacts these substances can have on their own life and that of their dependents. At the beginning, people only used drugs occasionally and were able to handle themselves in unusual situations. However, the scene has changed slowly as drugs have gained control over individuals and made them feel that they could not live without the drugs. The Executive Director of the United Nations Office on Drugs and Crime (UNODC) Yury Fedotov highlighted in the UN General Assembly special session on the world drug problem that, "There is much work to be done to confront the many harms inflicted by drugs on health, development, peace and security, in all regions of the world" (UNODC, 2016). Previously, various scholars had carried out a number of studies on drug addiction based on empirical data and secondary information. These studies underlined the seriousness and severity of the danger that drug addiction posed to individuals and society. It is sad to note that drug addiction has enslaved a significant percentage of the population in many countries of the world today. Drugs have exerted control over all human societies without any discrimination even in this supposedly enlightened era.

This drug addiction has become such a vexing global problem today that it needs to be addressed immediately. Not surprisingly, drug addiction has become one of the major social problems and a significant public health concern in Sri Lanka too (Silva \& Fonseka, 2008). The country has already lost many valuable people who contributed to the development of the country due to natural disasters and manmade disasters. Presently, drug addiction has been added to the list of social problems, and this is highly visible among the youth, the poor and working population in Sri Lanka.

This review article focused on one of the most worrying social problems existing in the world today, which is "Drug Addiction" by studying secondary data. These included publications by different authors such as books, journals, review reports, magazines, articles and websites, as well as the Handbook of Drug Abuse Information, Sri Lanka (2017). The objective of this study is to identify the drugs, assess the nature and extent of drug addiction, and the drugs expansion scene in Sri Lanka with the aim of raising awareness among the people to make the country free from drugs.

\section{Conceptual Framework of Drug Addiction}

Drugs are viewed as unnatural substances that are forced onto a society from deviant external forces. Many people in the world are alarmed about the use of drugs by the young and old and about its invasion into their societies. Drugs possess both positive and negative connotations that depend on the usage and the persons who use it. The mode of administration and the social class of the consumer influence the perception of drugs in traditional society. For instance, "cannabis" is considered a drug while alcohol is not considered as a drug in many countries. Further, doctors often use some of these drugs for medical purposes and prescribe them to treat various diseases and conditions. This kind of usage of drugs is widely accepted by society on the understanding that it is legitimate for medical purposes.

Commonly, drugs are categorized into two types as licit drugs and illicit drugs. Licit drugs are known as the legal drugs. Making, selling and using licit drugs is not prohibited. Alcohol, tobacco and caffeine are some examples of licit drugs in the market. Illicit drugs are prohibited, so it is illegal to make, sell or use them by anyone. Illicit drugs have been classified as illegal drugs because they are a threat to the health and life of the victims, as well as being a danger to the whole society. Heroin, cocaine, LSD, ecstasy, methamphetamine, amphetamines and hallucinogens are some examples of these kinds of drugs. Illicit drugs are highly addictive in nature and pose serious risks to those who use them in all ways (Brecher, 1972).

However, the psychoactive drugs that affect the central nervous system alter brain function resulting in temporary changes in a consumer's perception, thinking, mood, consciousness and behaviour. Therefore, they have acquired a negative image due to their weird effects and the resulting negative impacts. In this respect, a drug is defined as any substance, with the exception of food and water, which causes adverse changes in the functions of the body either physically and/or psychologically, when it is taken into the body through any route (Global Commission on Drug Policy, 2017).

There are a number of harmful drugs available legally and illegally in the market. Heroin, Cocaine, Barbiturates, Opium, Cannabis (Marijuana), Alcohol, Ketamine, Benzodiazepines, Amphetamines, Tobacco, Buprenorphine, Solvents, LSD, Ritalin, and Anabolic Steroids. GHB, Ecstasy and Khat are notorious drugs available in the back streets of the world. These drugs are regulated according to the degree of physical, psychological and social harm they can cause. Drugs are classified according to the level of harm posed by the drugs and the level of 
control exercised by the authorities. Heroin is ranked as the most harmful and most highly controlled substance in the world. Heroin, Cocaine and Barbiturates can cause a great deal of harm. Cocaine, Ecstacy and LSD are controlled very strictly, both locally and internationally. Alcohol, Ketamine, Benzodiazepines, Amphetamines, Tobacco and Buprenorphine have the potential to cause a moderate level of harm. Cannabis, Solvents, LSD, Ritalin, Anabolic Steroids, GHB, Ecstasy and Khat can cause limited harm. Alcohol, Ketamine, Tobacco, Solvents, Anabolic Steroids and Khat are not subject to any international control or regulation (Nutt, Leslie, Saulsbury \& Blakemore, 2007).

Drug addiction can occur as the result of someone trying out a drug due to peer pressure or out of curiosity, then consuming it occasionally and eventually becoming addicted to the drug; thereafter he/ she becomes enslaved to that drug. Drugs are often characterized as a substance that is powerful, seductive and rapidly addictive, so that anyone who tries it out is at the risk of addiction. Drug addiction is considered a complex disease as it alters the brain in such a way that it is very difficult for a person to quit the habit even though he may want to do so (Global Commission on Drug Policy, 2017). The National Institute on Drug Abuse (NIDA), based in US, defined drug addiction as a chronic, relapsing brain disease that is "characterized by compulsive drug seeking and use, despite harmful consequences" leading to very harmful and destructive behaviour (National Institute on Drug Abuse, 2016). Regular drug use affects the neural circuits of an addicted person's brain. Drugs control the ability of both the brain and the body, so motivating the person to repeat the action again and again. Long-term use of drugs affects functions like learning, judgment, decision-making, handling stress, memory, and behaviour of the person, which are essential mental processes required to lead a healthy and happy life in this world (Drug Facts, 2016).

Why do some people become addicted to drugs while others do not? There is no single factor that can lead to drug addiction but a combination of factors can push a person to take a dose of drugs to seek pleasure and satisfaction. There are two major factors that can contribute toward increasing the chance of drug addiction; one is inner motivation, which is a biological factor and the other one is the environment. Genes, gender, ethnicity and psychological disorders may influence a person's susceptibility to drug addiction by way of inner motivations. A person's external environment can play a very crucial part in drug related behaviour. Family, working environment, peer pressure, sexual harassment, previous experience with drugs, level of stress, degree of freedom, secularization trends, and guidance of others can strongly influence a person's drug related behaviour (Drug Facts, 2016).

The diverse effects and consequences of drug addiction are vast and varied and affect people of all ages. There are no positive impacts brought on by this drug addiction other than for the drug dealers who earn their money. Drug addiction can affect a person's health, physical fitness, psychological well-being, financial position, place in society, and finally have him charged with a criminal offence (Sussman \& Ames, 2001). The substances that he takes inside the body first strain the organs, then damage the organs, cause hormonal imbalance, lead to cancer, create parental and fertility issues, and other gastrointestinal diseases. Drug usage can also lead to contracting HIV/AIDS if contaminated hypodermic syringes are used for injecting the drugs. This drug addiction damages the psychosocial well-being of the person. Depression, anxiety, memory loss, aggression, mood swings, paranoia and psychosis are characteristic emotional effects of substance addiction. A sense of hopelessness, loneliness, fear, guilt, shame and unhappiness are some other negative emotions felt by drug addicts.

The social consequences of drug addiction make the life of drug addicts even darker. Social relationships and the intimate ties they have with others will also change, with peers, family members and co-workers tending to avoid the person (Sussman \& Ames, 2001). Dropping out of school, dismissal from employment, hospitalization and legal problems are common social consequences of drug addiction. These social effects start with the abusers and their family members. It may tend to disrupt family relationships because drug abuse may trigger domestic violence and the ensuing problems are known to lead to divorce actions (Sharma, 2009). Crimes committed by drug addicts will further damage the perception that society has about them. The direct and indirect economic costs of drugs are a serious challenge to the government bodies and relevant authorities. For example, the cost of running the government's drug enforcement policies and programmes is often higher than the cost of running many other services. Another significant economic burden is the loss of human productivity. Because of drug addiction, many workers cannot work properly, and this reduces their output and contribution to the economy. The hospitalization, medication and rehabilitation expenditures also prove to be a severe burden on the government. 


\section{Global Expansion of Drug Addiction}

Morbidity and mortality rates resulting from drug abuse have increased globally. According to the World Drug Report (2017), 29.5 million people across the globe suffer from drug use disorders. Out of the global adult population, $0.6 \%$ is highly vulnerable to drug use disorders. 'Opioid' type drugs are the most harmful in the world, being responsible for $70 \%$ of the negative health impacts. Usage of amphetamines has also increased the global burden of disease. 'Hepatitis $\mathrm{C}$ ' is causing much harm to 12 million people worldwide and posing a danger to the rest. Access to the treatment of drug addiction remains poor and very expensive in most countries (World Drug Report, 2017). The following are the leading drug consuming countries: Iran (Heroin, 14.32\% per capita), United Kingdom (Alcohol, 13.65\% per capita), France (Prescription Pills, 13.2\% per capita), Slovakia (Inhalants, $13.01 \%$ per capita), Russia (Alcohol, 7.1\% per capita), Afghanistan (Heroin, 6.9\% per Capita), Canada (Marijuana, 6.4\% per capita) and USA (Prescription Pills, 6.2\% per capita) (Global Outlook for Most Drug Addicted Countries, 2016).

Compared to other regions of the world, the prevalence of drug addiction is limited in Asia. The strict regulation and deterrent capital punishment in some countries are cited as reasons for the limited prevalence of drug habits among Asian people. In addition, the usage of illicit drugs has always been low in Asia. Culture, religious values and social norms among people also play a crucial role in limiting the desire of the youngsters for illicit drugs. Cambodia, Hong Kong, Philippines, Thailand, Indonesia, Laos, Malaysia, China, Myanmar and Vietnam are some examples of countries in Asia where moderate usage of drugs generally prevail. Official data relating to the prevalence of drugs usage are not available for some countries. Studies on drug addiction in Asia are also rare compared to other regions (Devaney, Reid, \& Baldwin, 2007). According to the World Drug Report of UNODC (2017), a high level of misuse of prescription "Opiods" was reported in many countries in Asia (World Drug Report, 2017).

Alcohol and drug abuse has become a highly visible social problem in South Asia too. India, Bhutan, Bangladesh, Nepal, and Sri Lanka are the countries mostly affected by drug abuse in this region. Heroin, Cannabis, Opium, and certain pharmaceutical preparations are the commonly abused drugs in these countries. Alcohol and tobacco use in combination with other drugs is also seen in these countries. Addiction to heroin by those below the age of 17 and cannabis usage by those in the 18-20 age group has been reported in this region. Along with the male addicts, female drug abusers are also on the increase in South Asian countries (Sharma, 2009).

All the countries in South Asia have comprehensive legal and regulatory systems in place to control the expansion of drugs. However, the problem is caused by improper implementation of the laws due to weak organization and lack of will of the officials. Smuggling is the main route of supply for drugs in South Asian countries. Drug dealers in India and Sri Lanka smuggle banned substances via sea-lanes. Bangladesh, India and Nepal smuggle drugs across land borders (Misuse of Prescription Drugs: A South Asia Perspective, 2011).

\section{Drugs in Sri Lanka}

Drug addiction was not considered a serious social problem in Sri Lanka until the early 1980s. It has now become a major issue due to its impact on public health, drug-related crimes, drug-induced diseases, poverty, and destruction of family life (Silva \& Fonseka, 2008). The experience of Sri Lanka in dealing with the drug abuse problem is unique in many ways. People have been taking drugs under Ayurvedic medical supervision in limited amounts from ancient times. The influence of the colonial masters was the major contributor to the expansion of illicit drugs in Sri Lanka from the sixteenth to the twentieth century. In particular, the colonial powers legitimized the use of opium as it could serve as a source of revenue for their respective kingdoms (Jayasuriya, 1995).

After the country obtained independence in 1948, the authorities took a number of initiatives to reduce the usage of drugs like Opium, Cannabis, and Psychotropic substances. Not all measures proved to be successful and the problem of drug addiction continued as there always happened to be a sufficient number of addicts in Ceylon, as Sri Lanka was known then. Furthermore, colonization, ethnic strife and riots in Sri Lanka had provided a favourable environment for drug smuggling across national boundaries. The absence of comprehensive measures and policies on drug abuse meant there was inadequate development of interventions for treatment and rehabilitation of drug addicts in Sri Lanka (Jayasuriya, 1995).

Further, the laws and policies on drug abuse that were implemented by the government to control drug addiction were not effective at restricting the activities of the drug trade, drug dealers and drug addicts in Sri Lanka. Every year, the number of drug dealers and consumers kept increasing, creating big problems. Fortunately, Sri Lanka being a multi-ethnic country with a rich tradition of culture, family ties and deep religious beliefs, possessed the 
ability and its own ways to control drugs, drug addiction and drug expansion within the country. Only a few studies have been carried out in Sri Lanka on drug addiction and its impacts, and these mainly focused on the quantitative measures relating to basic demographic and social conditions of the drug addicts in the country. However, studies on drug addiction should be conducted in a qualitative manner with sufficient information to make the people think more deeply than they do today, in order to create positive changes in the country.

Sri Lanka gets its supply of drugs from internal sources and external sources. Some drugs like Cannabis are illegally cultivated in Sri Lanka. Pharmacies play a crucial role in the drug scene in Sri Lanka. Pharmacies are the primary domestic players in the drug distribution network of the country. The pharmacists' personal user licence allows them to buy and supply pharmaceuticals beyond any limit. Most of these pharmaceutical drugs are imported into Sri Lanka from India. Smuggling from Pakistan also takes place routinely. Websites in the USA, UK, Europe, etc. also offer illegal drugs enabling pharmacies to place orders for drugs online (Misuse of Prescription Drugs: a South Asia Perspective, 2011).

\section{Drug Addiction in Sri Lanka}

According to the National Dangerous Drugs Control Board (NDDCB, 2017) of Sri Lanka, the total number of arrests related to drugs was 79,378 in 2016, which was an increase of $4 \%$ compared with 2015 . Of the total amount of seized drugs, $35 \%$ was heroin and $60 \%$ was cannabis. Sixty percent of the drug related arrests were reported from the Western Province, 9\% from the Southern Province, and 10\% from the Central Province. Forty-three percent of drug addicts were arrested in Colombo district, $13 \%$ from Gampaha district, and $4 \%$ from Kurunegala district in Sri Lanka. The incidence of drug related arrests was 390 per 100,000 people in 2017 (Handbook of Drug Abuse Information, 2017).

Based on the report of NDDCB (2017), the urban areas and main cities of the country are the most threatened by illicit drugs, with a higher level of drug prevalence being found in urban areas compared to rural areas. Drug related offences have also increased in Sri Lanka. In 2016, drug related prison admissions reached 24,060. Heroin and cannabis are the drugs most commonly taken by addicts in Sri Lanka. Compared with the usage of heroin, the consumption of cannabis is higher. The cannabis plant is cultivated in about 500 hectares in the dry zones of Sri Lanka, mainly the Northern, Eastern and Southern provinces. Cannabis is easy to cultivate with minimum labour input and fertilizers compared to other cash crops in Sri Lanka. Heroin is brought in by outsiders to the country; the uncontrolled arrival of tourists is the basic reason for this invasion of heroin. Foreign tourists who are addicted to this drug distribute it among interested and susceptible people. The usage of cocaine, opium and other substances is very low (Handbook of Drug Abuse Information, 2017). Figure 1 shows the drug related arrests for the different kinds of drugs.

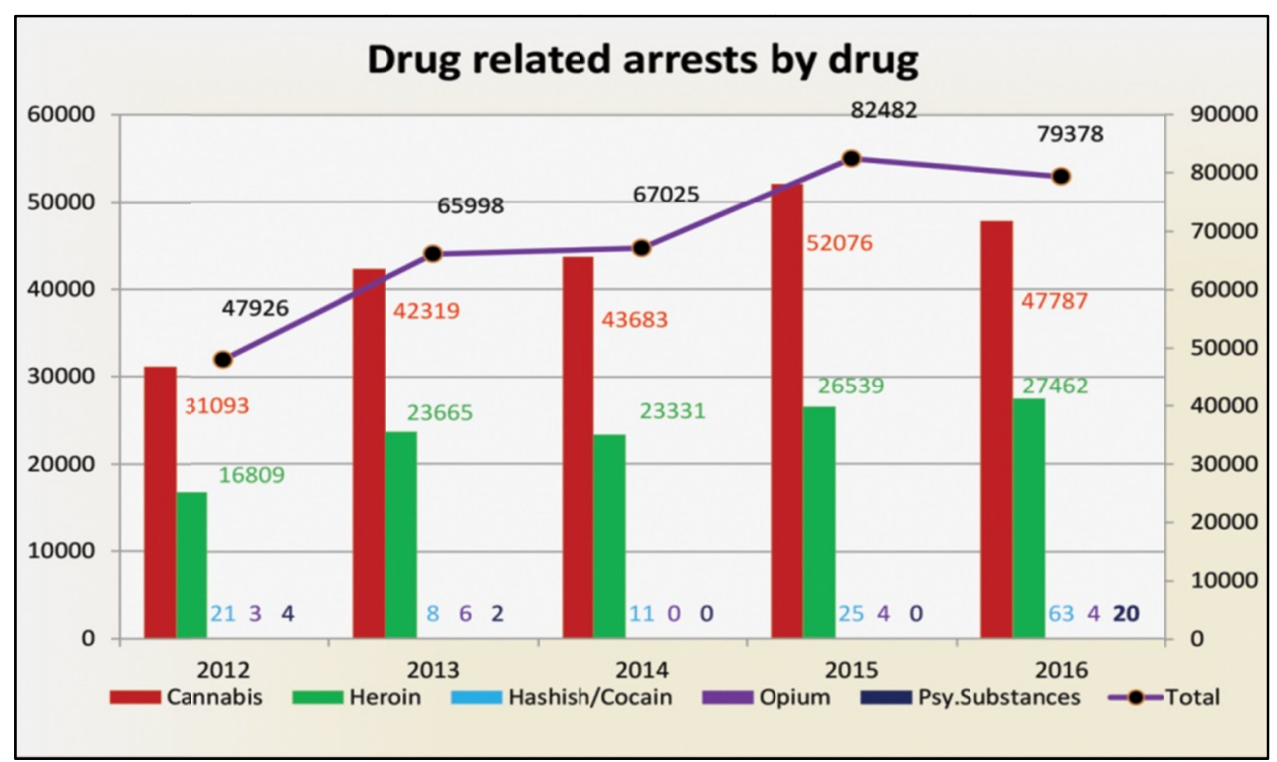

Figure 1. Drug related arrests by different kinds of drugs, 2016

Drug usage also increases the risk of HIV/AIDS infection because of the needles that are used to inject the drugs into the body. If drug users share the needles with other people, the chances of transmitting all kinds of diseases among themselves would be high. Based on official records, 2,557 HIV positive cases have been recorded in Sri 
Lanka. The prices of drugs are also increasing due to the strong demand from drug users in the country. The laws and regulations laid down by the authorities to monitor and control the use of drugs did not play a prominent role in limiting their consumption. People spent a large part of their earnings to buy these dangerous drugs. The average street price of drugs also increased due to the high demand for them in the country. For example, the average street price of heroin was LKR 9 million for one $\mathrm{kg}$ in 2016, which is a $13 \%$ increase over the average street price in 2015 (LKR 8 million per kg). The average street price of cannabis was LKR 22,000 per kg in 2016 and for opium it was LKR 1.5 million per kg. Figure 2 illustrates the market fluctuations in the average street prices of drugs (Handbook of Drug Abuse Information, 2017).

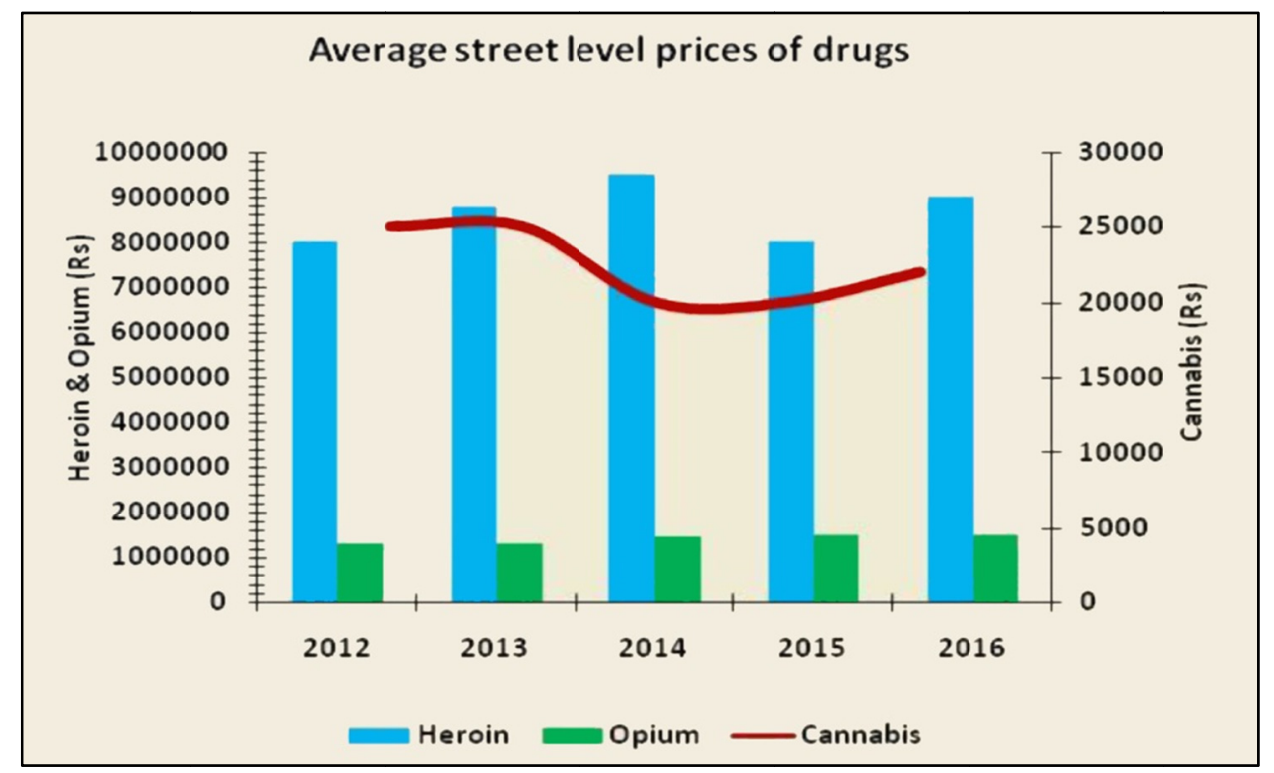

Figure 2. Average street level prices of drugs, 2016

\section{Institutional Care and the Role of Rehabilitation Centres in Sri Lanka}

According to official records, drug addiction in Sri Lanka has increased sharply in recent times. This drug addiction has a profound negative impact on individuals, family, society and eventually the development of the whole country. According to a study by P.V. De Silva and P. Fonseka on the behaviour of institutionalized drug addicts in Galle District (2008), rehabilitation of drug addicts has become an urgent need in the country if its valuable citizens are to be saved, as their contribution too is necessary to build a sustainable nation. The National Dangerous Drugs Control Board, which was established in 1984, has implemented a number of policies and programmes to address this issue, under the direction of government. A Non-Governmental Organization (NGO) started the first drug rehabilitation centre in 1987. Later, the government and private bodies too started rehabilitation centres all across the island to save the drug addicts from their folly (Silva \& Fonseka, 2008).

Currently, the Sri Lankan government and non-governmental organizations are providing residential care treatment and rehabilitation services for drug addicts in the country. A drug dependent person is forced to obtain treatment to overcome his addiction to drugs. Four residential treatment centres are operating in Sri Lanka under the purview of the NDDCB, and they are located in Colombo, Kandy, Galle and Nittambuwa. Family counselling, which includes detoxification treatment, physical exercises, mental relaxation, indoor and outdoor activities, psychotherapy, educational and vocational training, coping skills and motivation to develop healthy lifestyles are the major treatments provided by these rehabilitation centres (Handbook of Drug Abuse Information, 2017). Family counselling is indispensable to drug dependents. This kind of family counselling makes the drug dependents aware of the importance of having a good family life. Counselling also places stress on their duty and obligation to support their family and lead the family throughout their whole life. Educating the drug users, giving them advice, and providing them therapeutic treatment will go a long way towards filling them with confidence and hope, as that will greatly improve their chances of complete recovery. These sorts of activities given in the vocational training centres prove very helpful as they empower the drug addicts to rid themselves of their addiction and start a new life that is free of enslavement to drugs. They can expect a better future by holding a steady job and enjoying decent living conditions for themselves and their families. 
There were 2,355 drug dependents being treated island wide in rehabilitation centres in 2016. The number of persons admitted for treatment increased by $59 \%$ in 2016 compared to 2015 . Fifty-one percent of the drug dependents were treated in Colombo District (Handbook of Drug Abuse Information, 2017). An urban setting plays an important role in influencing human behaviour too. Figure 3 shows the number of drug addicts admitted for treatment from 2012 to 2016; in 2012 the number admitted for treatment was 1,109 and this figure gradually increased to 2,355 in 2016.

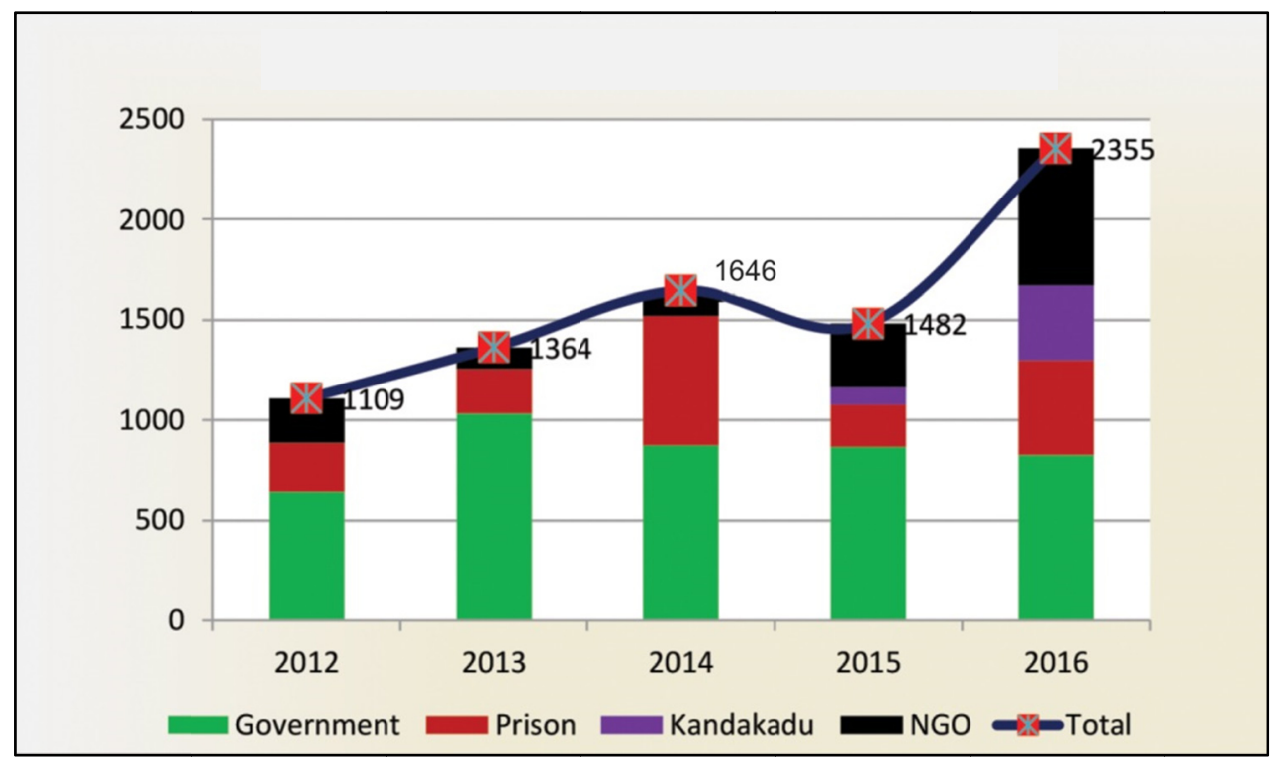

Figure 3. Number of persons admitted for treatment, 2016

The study of Silva and Fonseka on drug addicts and their behaviour was conducted with the institutionalized addicts in Galle District (2008) as the subjects. This study highlights that the majority (99\%) of the drug-addicted population in the rehabilitation centre comprised males (Silva \& Fonseka, 2008). This situation reflects the overall picture in Sri Lanka. The Handbook of Drug Abuse Information (2017) reported that Sri Lanka has a very low number of female drug addicts compared to other countries.

\section{Preventing Drug Addiction is the Best Strategy}

Drug addiction has become a serious psychosocial problem in Sri Lanka because in spite of the authorities putting in a lot of effort to discourage drug usage, people somehow manage to get addicted to various kinds of drugs that are available in the market. Drug addiction is considered as a disease in which the human brain becomes enslaved to drugs. As responsible human beings, everyone in society needs to avoid a situation in which drugs take control of our minds and enslave us. Only the drug dealers benefit from all this by making a huge amount of money from the drugs they distribute to misguided persons in the society. Drug addiction slowly destroys the physical, psychological, and social well-being of drug abusers. Drug addiction is considered as an avoidable evil in society. As drug addiction leads to abnormal behaviour patterns, people tend to avoid interacting with those persons who are addicted to drugs.

According to Emile Durkheim's theory of suicide, if a person feels socially isolated and generally overlooked by the society in which he grew, that could lead him to commit suicide (Durkheim, 1951). Drug addiction has adverse effects on the individual, family, society, and the country. The number of drug addicts is increasing on a daily basis and they come from every stratum of the society in Sri Lanka. Despite the contributions of many social institutions, it has not been possible to rehabilitate certain individuals and free them from the tenacious hold of drugs even after expending a lot of effort. According to the available statistics, most of the heroin abusers are found to be youngsters. Notably, the drug kingpins who supply the drug dealers wield a lot of power in the illegal and underground network of the drug market. These drug kingpins enjoy a high standard of living and outwardly lead very respectable lives in society, but their deplorable drug dealing activities in the underground market destroy the poor and innocent people's lives on a daily basis.

Drug addiction is generally not treatable in the same way as other physiological diseases like asthma, heart disease, and diabetes. Nevertheless, it is treatable and can be managed successfully. International organizations and national governments have formulated a number of plans and policies to tackle the issues concerning drug 
addiction. Rehabilitation centres play a crucial role in helping drug addicts to reclaim their lives again. If one asks a question like, which do you prefer, treatment for drug addiction or drug prevention, nearly all members of the society would choose the latter.

Drug addiction is preventable. In keeping with the proverb, "Prevention is better than cure," society should go ahead and implement preventive measures against the usage of drugs. Prevention programmes involving all family members, all students, all communities, and the media should be launched for preventing and reducing drug usage and drug addiction in Sri Lanka and every other country. The aim of prevention strategy programmes on drugs is to raise awareness among youngsters and other people. They should make people realize the harmful effects of drugs so that they will also mobilize to reduce and prevent the use of drugs on their own. Especially, it is important to include drugs prevention programmes in the school curriculum in order to educate the youth about the dangers posed by drugs. Conducting awareness programmes and discussions among the public is very important too, so that people will have a better understanding of the negative social impacts of drug addiction. Not only the policymakers but also other parties like parents, teachers, and healthcare providers should put in the effort to educate people about the dangers posed by drugs in order to promote a healthy life for all in Sri Lanka.

\section{Conclusion}

There are many social problems prevailing in the world. Drug addiction is one of the more vexing social problems in the modern era of globalization. Millions of people across the world have lost control of their own lives by falling prey to drugs. There are a number of harmful drugs available legally and illegally in the market in practically every city. Internal biological and external environmental factors contribute to increase the chances of drug addiction. The unpredictable effects and consequences of drug abuse are wide ranging and can affect people of all ages. For example, they can affect a person's health, physical fitness, psychological well-being, and finances.

Drug addiction has become a major problem in Sri Lanka as it destroys the life and soul of the people. Heroin and cannabis are found to be the most consumed drugs in Sri Lanka. Laws and policies aimed at controlling drug abuse and drug addiction have not brought any major changes or the desired outcomes in Sri Lanka, with the underground drug market continuing business as usual. Drug users in Sri Lanka get their drugs from internal sources and external sources. Prevalence of drug usage is higher in urban areas compared to rural areas in Sri Lanka. Drug related offences have also increased in all parts of the country.

Rehabilitation of drug addicts has become an urgent need of the hour to rescue the valuable citizens from the clutches of drugs to build a sustainable country. Currently, the Sri Lankan Government and Non-Governmental Organizations are providing residential care treatment and rehabilitation services for drug addicts who are found across the country. Drug addiction is preventable and can be managed successfully if all citizens give their full support and contribute as necessary. Together with other comprehensive plans, policies and programmes to overcome the drug menace, people from all walks of life should participate to eliminate drug addiction and the drugs trade in Sri Lanka.

\section{References}

Blvd Treatment Centres. (2016, May 3). Global Outlook for Most Drug Addicted Countries. Retrieved March 22, 2018, from https://www.blvdcenters.org/blog/top-8-drug-addicted-countries.

Brecher, E. (1972). Licit and Illicit Drugs. Boston, United States: Little, Brown and Company.

Brill, L. (1966). Drug Abuse as a Social Problem. International Journal of the Addictions, 1(2), 7-21. https://doi.org/10.3109/10826086609026748

Devaney, M., Reid, G., \& Baldwin, S. (2007). Prevalence of Illicit Drug Use in Asia and the Pacific. Drug and Alcohol Review, 26(1), 97-102. https://doi.org/10.1080/09595230601037034

Dissabandara, Lakal, Dias, R., Shavindra, Dodd, R., Peter, et al. (2009). Patterns of Substance Use in Male Incarcerated Drug Users in Sri Lanka. Drug and Alcohol Review, 1-22. https://doi.org/10.1111/j.1465-3362.2009.00062.x

Durkheim, E. (1951). Suicide. London: The Free Press.

Giddens, A. (2001). Sociology (4th ed.). Cambridge: Polity Press.

Global Commission on Drug Policy. (2017). The World Drug Perception Problem: Countering Prejudices About People Who Use Drugs. Geneva: Global Commission on Drug Policy.

Handbook of Drug Abuse Information. (2017). Colombo: Youth Services Press. 
Jayasuriya, D. (1995). The Drug Abuse Problem in Sri Lanka. Medicine and Law, 14(1), 37-43.

Misuse of Prescription Drugs: a South Asia Perspective. (2011).New Delhi: United Nations Office on Drugs and Crime.

National Institute on Drug Abuse. (2016, August). Drug Facts. Retrieved February 15, 2018, from http://www.drugabuse.gov

National Institute on Drug Abuse. (2016, October). The Science of Drug Abuse and Addiction: TheBasics. Retrieved March 14, 2018, from https://www.drugabuse.gov/publications/media-guide/science-drug-abuse-addiction-basic

Nutt, D., Leslie, A., Saulsbury, W., \& Blakemore, C. (2007). Development of a Rational Scale to Assess the Harm of Drugs of Potential Misuse. The Lancet, 369(9566), 1047-1053. https://doi.org/10.1016/S0140-6736(07)60464-4

Rao, S. (1990). Sociology: Principles of Sociology with an Introduction to Social Thought. New Delhi: S. Chand \& Company Ltd.

Sharma, U. (2009). Social Consequences of Drug Abuse in South Asia. National Institute on Drug Abuse.

Silva, P., \& Fonseka, P. (2008). Drug Related to Drug Addiction among the Institutionalized Addicts of the Galle District. Galle Medical Journal, 13(1), 9-13. https://doi.org/10.4038/gmj.v13i1.886

Sussman, S., \& Ames, S. (2001). The social psychology of drug abuse. Buckingham: Open University Press.

World Drug Report. (2017). Vienna: United Nations Office on Drugs and Crime.

\section{Copyrights}

Copyright for this article is retained by the author(s), with first publication rights granted to the journal.

This is an open-access article distributed under the terms and conditions of the Creative Commons Attribution license (http://creativecommons.org/licenses/by/4.0/). 